\title{
A review of methods of cartographic presentation of urban space
}

\author{
Joanna Bac-Bronowicz ${ }^{1, *}$, and Gabriela Wojciechowska ${ }^{1}$ \\ ${ }^{1}$ Wroclaw University of Science and Technology, Faculty of Geoengineering, Mining and Geology, 27 Wyb. Wyspianskiego St., \\ 50-370 Wroclaw, Poland
}

\begin{abstract}
The aim of the article is to present selected solutions applied in urban planning, which, even contemporarily, can be used as models. The paper presents a review of selected concepts of model cities from the antiquity to contemporary times. The article presents methods of creating three-dimensional city models (or their flat presentations in so-called two and a half dimensions), including the historical conceptualization, portraying both the practical and aesthetical features of former map projections. Referring to historical examples, the article also includes historical and contemporary urban 3D models corresponding to analyzed conceptions.
\end{abstract}

\section{Introduction}

Portraying of the surrounding reality has been an immanent element of our civilization since its beginnings. Since the prehistory, depending on the predominant aesthetic movement, the imagery of surrounding environment was presented through the means of cave paintings, rock reliefs (Fig. 1), as well as paintings in interiors of temples and other structures.

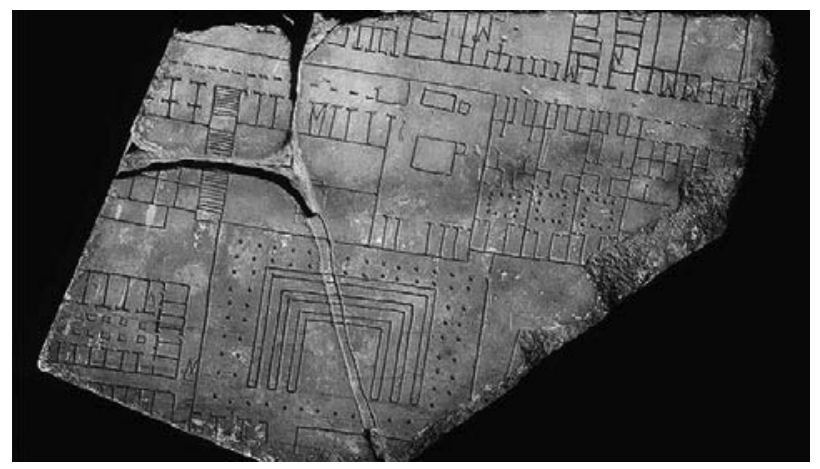

Fig. 1. Forma Urbis Romae, approx. 200 AD [1].

Maps serve numerous important functions, such as: historical, social, cultural, educational, directional, cognitive, operational and guiding. The guiding function is also an important property of town maps and tourist maps [2]. Graphic notation has been serving people since the beginnings in order to create holistic spatial imageries which enable them not only the identification of landmarks and their spatial layouts, but also acquiring the knowledge concerning the unknown places, both existing and artificial, through the means of analogy [2].

Cartographic methods have developed significantly over the recent years. Thanks to the use of computer technology, it seems that the possibilities of precise cartographic representation are endless. Changes in remote sensing made it possible to collect increasingly accurate $3 \mathrm{D}$ data concerning the environment, as well as information about new products and services in 4D. It is believed that a number of changes in cartography during the next five to ten years will be caused by 4D cartographic products [3].

It is believed that the increase of urbanization will present a global challenge for cartography. The analysis of data concerning the course of global urbanization reveals that the population in cities increases threefold quicker than the average global population. The United Nations estimate that, by the year 2050, the global population will amount to over 9 billion, of which $80 \%$ is estimated to live in urban settlements. As a result, the notion of Smart City was coined. In general, it may be assumed that the above term refers to a certain idea of style and functioning of a city, or its management described in the language of modern technologies. Problematic aspects of smart cities are both multifaceted and multi-dimensional, as they incorporate humanistic, social, environmental and technological problems [4]. Intelligent systems will be used in order to develop new ways of presenting the complex spatial relations to their observers. The development of augmented and virtual reality will enable people to work with data in a new way. The integration of smart technologies and efficient city management models for sure will require quick, automated digital cartographic models with possibly highest data quality.

Representations of cities will cease to include merely presentations of external development. Current techniques used for analysis, modelling and presentation of geoinformation become increasingly improved and enable creation of virtual city models aiming at management of urban infrastructure. Apart from praising

*Corresponding author: joanna.bac-bronowicz@pwr.edu.pl 
the infinite number of current possibilities, it is also important to take notice of changes in cartographic presentations of cities which occurred during the history.

Among numerous cartographic presentations those which present projections crucial for the development of the history of cartography have been selected, reflecting the character of a given period. When analyzing historical reports, it is worth noticing that, despite the location and time period, city plans have always had an important cultural aspect. By presenting the available knowledge concerning the surroundings, maps raised and increased awareness of many societies. Moreover, maps are a necessary element in gaining knowledge concerning the surroundings and presenting projects related to spatial development.

The aim of the article is to present selected solutions applied in creation of city maps, which might serve as models even in the contemporary day and age.

\section{Urban cartographic representations - from antiquity to contemporary times}

The following part of the paper presents selected examples of cartographic representations of cities, which illustrate the most prominent art movements which influenced the development of this field of knowledge, as well as those which are considered as groundbreaking in the course of history of cartography. It commonly occurs that the same discoveries are made several times during the course of history. Some inventions become forgotten due to the collapse of civilizations, just to be rediscovered in the following ages. We are aware that metric plans were known to certain ancient civilizations, it is also commonly known that during the Medieval Period they were forgotten only to be rediscovered during the times of the Renaissance and, until today, considered as basic cartographic representations of cities.

The development of cartographic maps and methods of representations of cities were connected with the perception of reality and artistic practices characteristic for a given epoch. Aspective art, which was also known in Bronze Age, was often used by, among others, ancient Egyptians, who depicted three-dimensional objects by combining their views from above and from the side. Such representations were commonly used in Medieval maps, e.g. the map of Jerusalem from 1120 from the chronicle by Robert of Saint-Remy [5] and Mappa mundi from Ebstorf (Fig. 2) - where one plane combines a group of communications routes and depictions of building facades. It is widely believed that not many city maps were created in Medieval Europe. Regular use of maps and urban plans was limited to very few specific areas. The idea of making a draft of a map in order to showcase topological and topographical relations (roads connecting particular locations, layout of fields, order of houses along a street) was not popular in the Middle Ages. Medieval maps of small areas and regions were in its time quite unusual realizations, oftentimes presenting substantial originality and ingenuity of the author who might have never seen a map drawn up by someone else.
In the Middle Ages it was common to present topographic relations in writing, therefore, descriptions were preferred over maps [6].

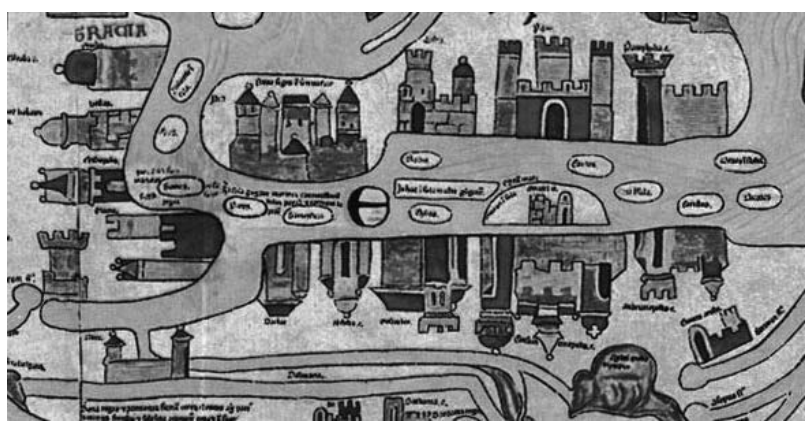

Fig. 2. Part of the map from Ebstorf, approx. 1300 [7].

The second half of 13th century is the time of considerable advancements in representation of space and search of a logical conception of object depiction. Former perspective primitiveness is gradually replaced by a type of parallel perspective, often unhampered by the rules of geometric representations, in order to evolutionally transform into linear perspective (the elementary principles of its creation were determined already in 15th century) [8].

Parallel perspective (used in the art of Far East and ancient Greece) uses diagonal presentation in order to depict structures spatially; both the façade and depth are visible. Buildings which are further away are placed higher than closer ones, however their size is not changed. According to W. Strzemiński, visual awareness is conditioned by the process of historic transformations. Linear perspective, which is currently considered as traditional perspective and which corresponds to natural human vision, was oftentimes rejected in ancient Greece. Plato considered painters who created using the said technique as creators of illusions and liars [9]. It was a new perspective which surprised his contemporaries as it did not comply to their visual awareness.

The Paris map (Fig. 3) published by Olivier Truschet and Germain Hoyau in mid-16th century [12], is an interesting instance of urban cartographic representation created with the use of parallel perspective. The map contains schematically presented buildings together with ensuring the visibility of streets and their names, as well as information concerning places of importance for the inhabitants, i.e. the location of the place of ball games or trail of upstream barge haul. Former depictions of cities are invaluable sources of information concerning their development. They may serve as source material for the historical reconstructions of urban planning schemes, i.e. Fig. 4., which presents the reconstruction of 14th century Paris with the view of la Sainte Chapelle, made by Dassault Systèmes. Admittedly it is a reconstruction of a period earlier then the aforementioned map, nevertheless, it presents the current possibilities of virtual reconstruction. Reproduction of cartographic legacy in a digital form grants a new possibility of maintaining and examining historical cartography. Digital techniques currently applied in cartography enable a georeferential analysis of historical maps. 
Combining of the knowledge of cartographers, architects, historians and urban planners makes it possible to reconstruct the historical layout of an urban settlement together with attributes of reconstructed facilities. An example of such works is the first urban map from the 19th century Gregorian cadastre in Bolonia [13]. In the above study the researches used GIS tools as well as 3D modelling and historic sources in order to analyze the image of the city from the perspective of proprietorship of its inhabitants. The analysis of 19thcentury layout of the city was conducted after the conversion of information into a georeferential 3D model enabling synthetic analysis of ownership aspects, which, prior to the analysis, were not noticeable during the direct inspection of documents. An additional advantage of the model is digitalization of original documents, which were desired to be accessed by researchers.

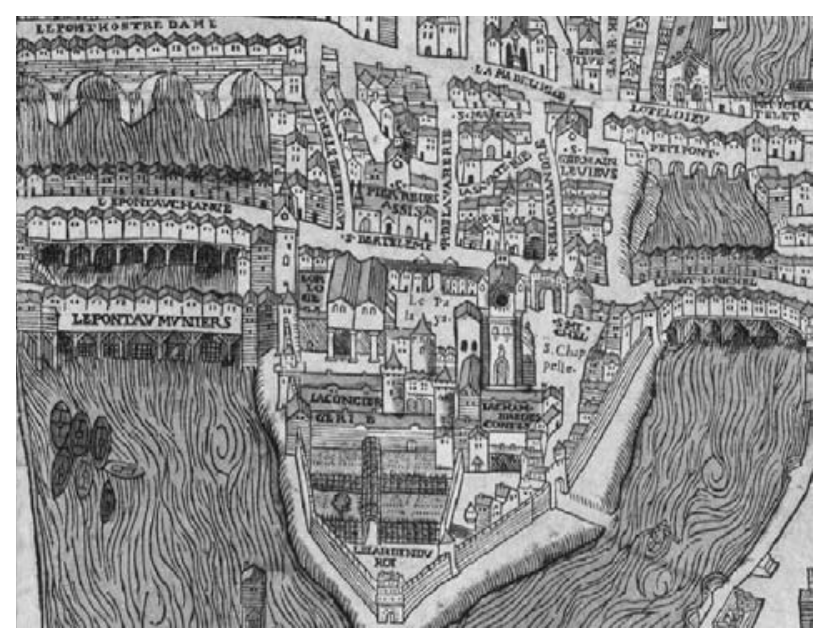

Fig. 3. Part of the Paris map from approx. 1550 [10].

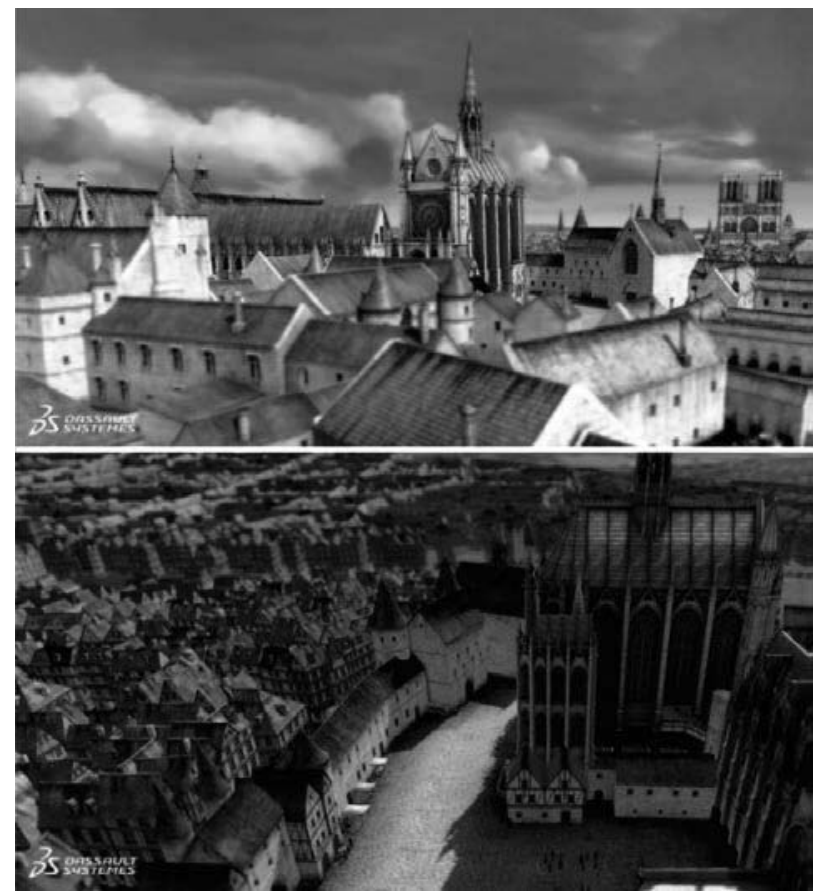

Fig. 4. Reconstruction of 14th century Paris by Dassault Systèmes (the view of la Sainte Chapelle) [11].
Together with the development of the theory of perspective, the representations of cities became increasingly common. One of the milestones in 3D cartography is the map of Venice (Fig. 5) from the year 1500 created by Jacop de Barbari, the apprentice of Albrecht Dürer [14], which is one of the first bird's eye view representations of the entire city in history. The map was depicted on six woodcuts; its precision, together with the fact that many of the buildings from that period still remain intact, enable touring the city with the use of the said map even today. Fig. 6. presents the contemporary outlook of Venice obtained with the use of satellites, published by Google Earth portal. The comparison of both depictions shows the mastery of creators of the Renaissance map, who were able to capture the reality using only basic tools and their imagination. The accuracy of this historic representation (Fig. 7) is so high that it is easily possible to find characteristic facilities and examine the changes which took place in the historic development over last 500 years.

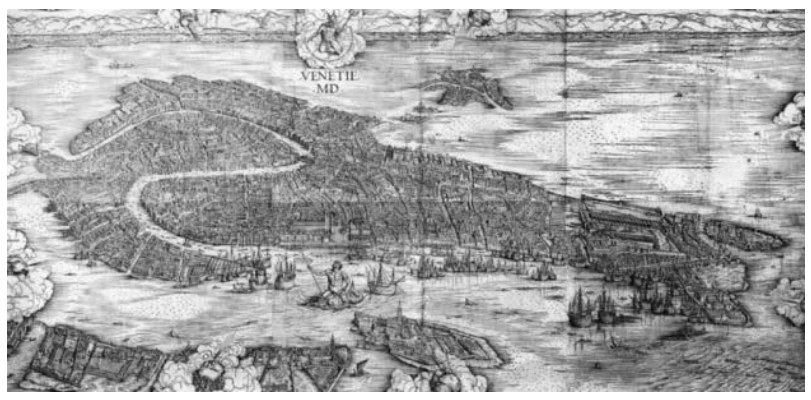

Fig. 5. Map of Venice by Jacopo de Barbari (approx. 1500 r.) [15].

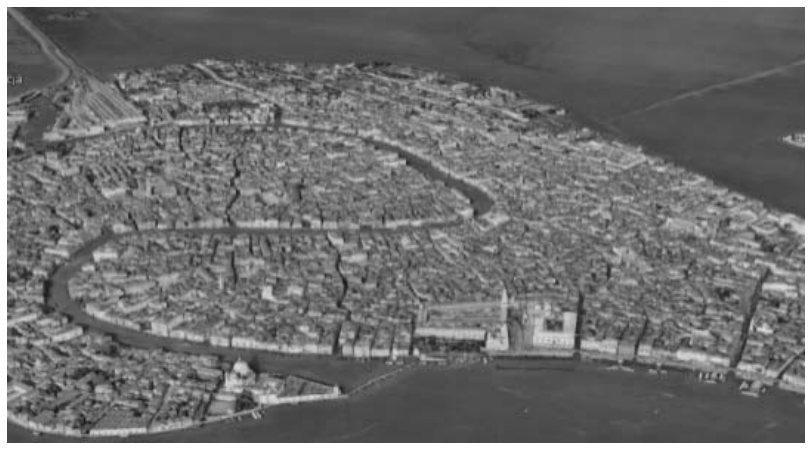

Fig. 6. Venice in 3D, Google Earth [16].

City maps enabled not only to localize places in the surrounding space and manage the area, but they also were symbols of power and dominance of a particular urban settlement.

Together with the development of illustration techniques and measurement methods the maps became increasingly perfected. There is a strong relation between art and cartography, as, especially during the period of the Renaissance, painters were often authors and coauthors of maps (A. Dürer, L. da Vinci, J. van Eyck). 


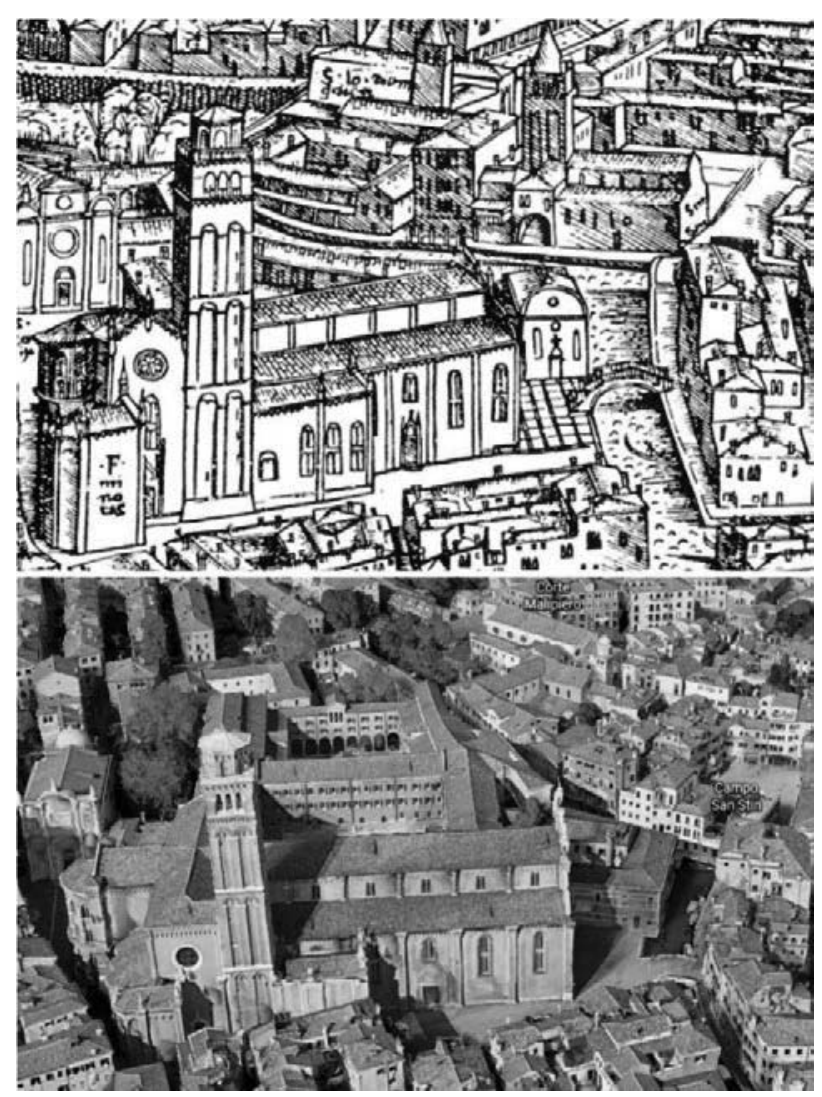

Fig. 7. Basillica Santa Maria Gloriosa dei Frari represented on the map of Venice by Barbari and a 3D view from Google Earth $[15,16]$.

The map of Milan by Leonardo da Vinci is considered to be a breakthrough in the history of cartography (Fig. 8), as it is believed to be the first cartographic attempt to transfer the observations from the ground level to the bird's eye view with sheer use of artist's imagination, which was in opposition to the contemporary representations of cities painted from a specific point as perspective views. Da Vinci drew the three-dimensional view of Milan using the principles of mathematical perspective basing on the obtained projection [17]. In his latter cartographic works, da Vinci continued creating two-dimensional map representations, such as those known in modern cartography, rejecting the bird's eye view, i.a. Imola town map. Twodimensional cartographic representations of cities were also created by Alberti, who was the author of the map of Rome, which unfortunately was not preserved and is known only from its descriptions [17].

Former maps often contained representations of urban panoramic views. By the end of 15 th century flamboyant maps and urban outlooks became popularized in royal, papal and aristocratic palaces, where they served both informative and decorative function. Urban views were the most popular cartographic images in the Renaissance and their popularity was so high that they were often encountered in such publications as Braun and Hogenberg's Civitates orbis terrarum and used for interior design. They were deliberately placed in the suites intended for prominent guests in order to impress them with representations of surrounding areas. Since the second half of 15 th century urban views appeared also as painted cycles, which gained even more popularity. The meaning and functions of painted cycles with the city view did not differ significantly from the cycles of maps, although they constitute a separate group [19].

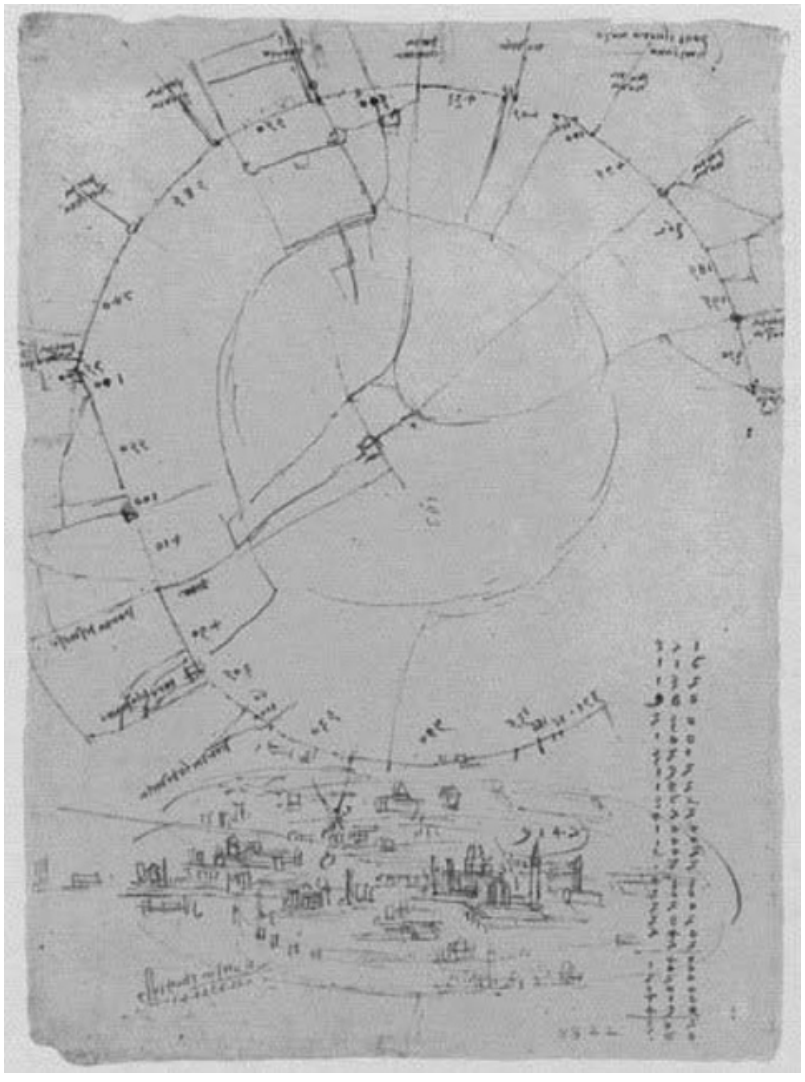

Fig. 8. Plan and view of Milan, Codex Atlanticus (1478-1519) [18].

Renaissance cartography features maps of so-called ideal cities - which served as examples of the search for perfect dwelling space. The design assumptions applied in those works emphasized the aesthetics and symmetry, which is clearly visible in cartographic representations of those layouts. The Renaissance brought about change in the perception of a city. Since 15 th century, city has become an observed and analyzed phenomenon. Together with its studies new theories concerning the ideal city form were developed. It was also the time of perfection of presentation - the Renaissance marks the beginning of the use of perspective. The Renaissance space was highly ordered and unified, shaped according to rigorously applied proportions [20]. In 16th century numerous model cities were planned, for instance, functioning until this day, model city, star fort Palmanova, Italy (1593) by Vincenzo Scamozzi and Zamość, nicknamed as the Pearl of the Renaissance and "Padua of the North". Zamość, located in the eastern part of Poland, is a realization of a Renaissance model city designed by an Italian architect, Bernardo Morando. Its construction was commenced in 1579 and it was commissioned by Jan Zamoyski, who wanted to build the headquarters and an impregnable fortress for his family, which would stun with its architecture. The town 
was included in the UNESCO World Heritage List in 1992 (Figs. 9, 10).

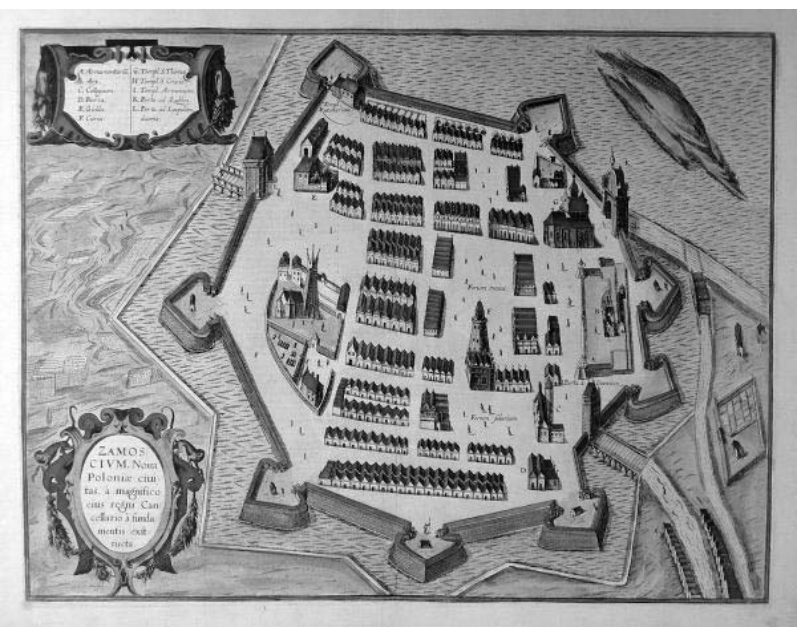

Fig. 9. Plan of Zamość by Georg Braun and Franz Hogenberg, 1617 [21].

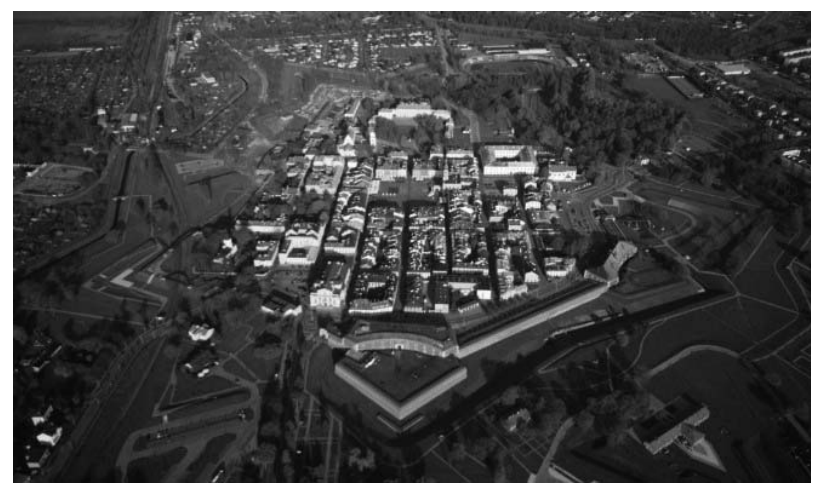

Fig. 10. Contemporary view of Zamość, fot. M. Poznański [22].

It is also worth noticing that old maps were created in various purposes - in some cases the way of graphic presentation was strongly dependent on the purpose and function of the map. It is also crucial to mention the use of intentional perspective, which considered the hierarchy of depicted structures in the pictorial representations - more important objects were painted bigger. An example of a map with a purposeful distortion of the imagery may be the map of Moscow from 1610, which currently would be qualified as an anamorphic map. Throughout centuries, the anamorphic conceptualizations were a natural way of notation and understandable form of transfer of information, which is evidenced by: drawings of trade routes, Roman operational military maps, pilgrim maps, the abovementioned Polish "spy" map of Moscow (Fig. 11), or an 18th-century draft of contemporary dioceses of north Poland. Violation of the Euclid rules in case of the aforementioned models resulted in the increase of their functional qualities e.g. for the troops besieging Moscow it was the courses of trackways from the gates of the city towards the Kremlin, which were accentuated due to purposeful extending [2]. The actual course of trackways is presented on the Moscow map from 1597 (Fig. 12).

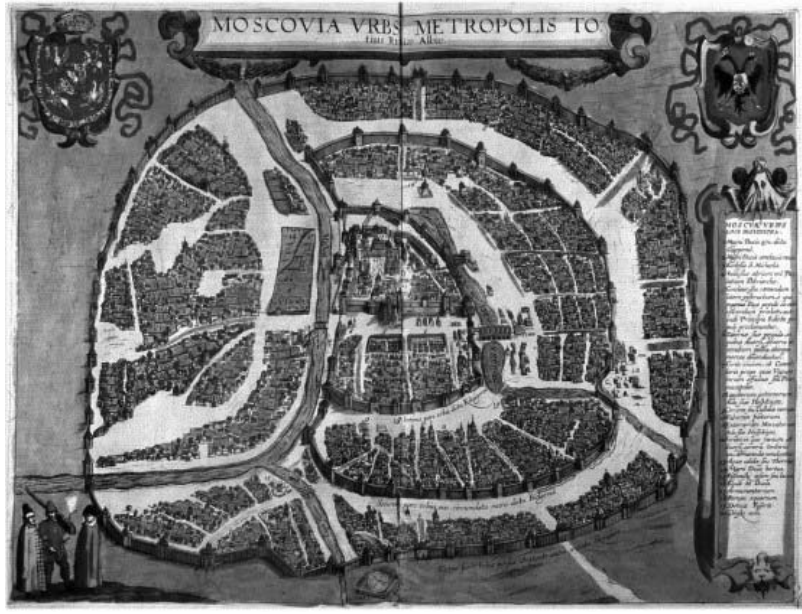

Fig. 11. Map of Moscow, 1610 [23].

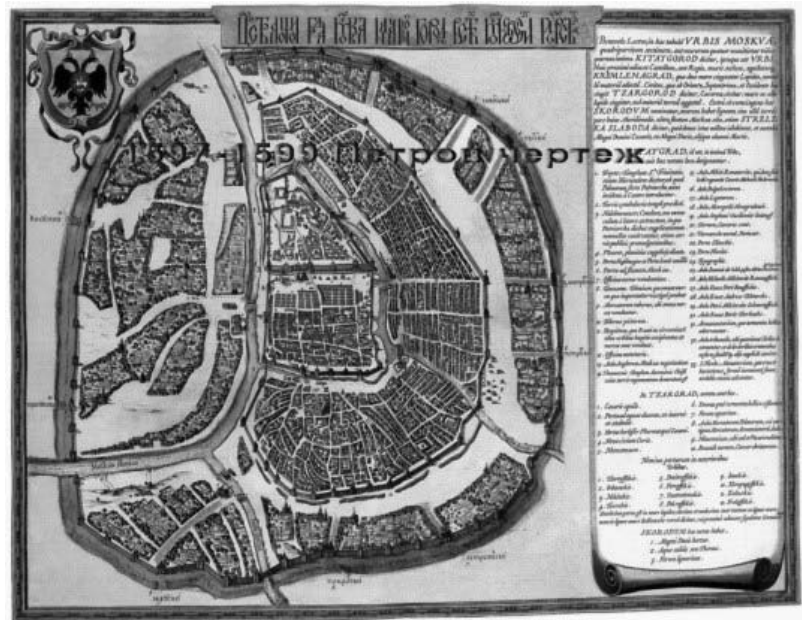

Fig. 12. Map of Moscow, 1597 r. [24].

Together with the development of cartography, conventional markings replaced pictorial images. Gradual division between cartography and art commenced with the introduction of new tools and techniques of measurement, which began to replace works of artists as early as in 15 th century. What is more, even after the establishment of new scientific measurements in 17 th century, the techniques of landscape sketching still maintained a direct relation between cartography an art and in doing so remained useful for natural scientists, engineers and soldiers [17].

Popular projections on 17th-century maps drawn up basing on direct measurements were urban dioramas, sometimes even urban plans, as well as chorographic presentations in the form of imponderables, which oftentimes artfully combined science and art. Such way of presentation of urban landscape may be observed, for instance, on a map of the Mediterranean Sea created by Pierre Mortier in Amsterdam in 1694.

18 th century is the period of Enlightenment, which might be called as the era of maps. The concept of a geographic map was fascinating for the contemporary, as it embodied the complex discipline of "mathematical cosmography". Governmental and administrational institutions became to rely more strongly on maps in order to regulate and control their territories. Developing 
printing and visual culture led to creation of maps both in the form of manuscripts and prints, such representations were created in accordance with common aesthetics of layout and design [25]. Graphic representations oftentimes were lacking in "unnecessary decorative elements". Conventional design and presentation standards influenced also topographic and other big-scale maps. That period is also the time of creation of city maps (2D) with high accuracy and detailing of presentation together with high quality of graphics. Fig. 13 presents original cartographic presentation from 1705 depicting generalized highdensity city blocks in Paris from the period of 14221589 .

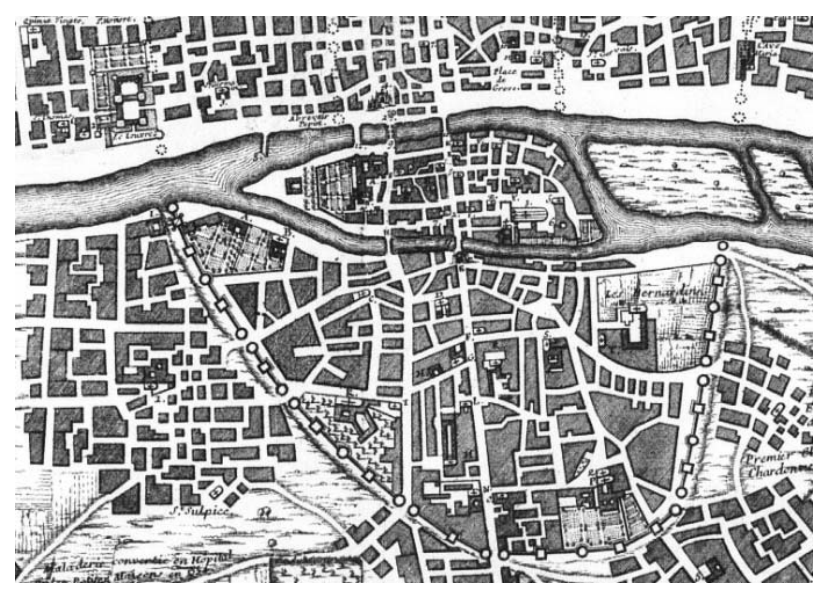

Fig. 13. Fragment of plan of Paris in 1589 (from 1705), the sixth of eight chronological maps of Paris from Traité de la police by N. de La Mare [26].

$19^{\text {th }}$ century is the age of cartography and popularization of thematic maps. Creation of maps became institutionalized, specialized and professionalized. The need for maps was constantly increasing - as a result of the development of tourism, mass education and introduction of cheaper printing techniques, as well as creation of new urban infrastructures, which led to spreading of cartographical knowledge and development of corporate producers of maps. Industrialization influenced the aesthetics of map design, partially determined by new printing technologies and introduction of color printing. One of the most well-known urban maps from that period is Descriptive Map of London Poverty from 1899 by Ch. Booth depicting the complexity of social geography of the city [Fig. 14]. The degree of wealth of inhabitants was marked using a colored scale.

$20^{\text {th }}$ century marked a breakthrough in the history of maps. The transition from the paper to digital format resulted in incredible changes as it commenced the era of dynamic and interactive maps [28]. Systems of geographic information radically changed cartographic institutions, while satellite positioning and mobile communication revolutionized the way of searching for information.

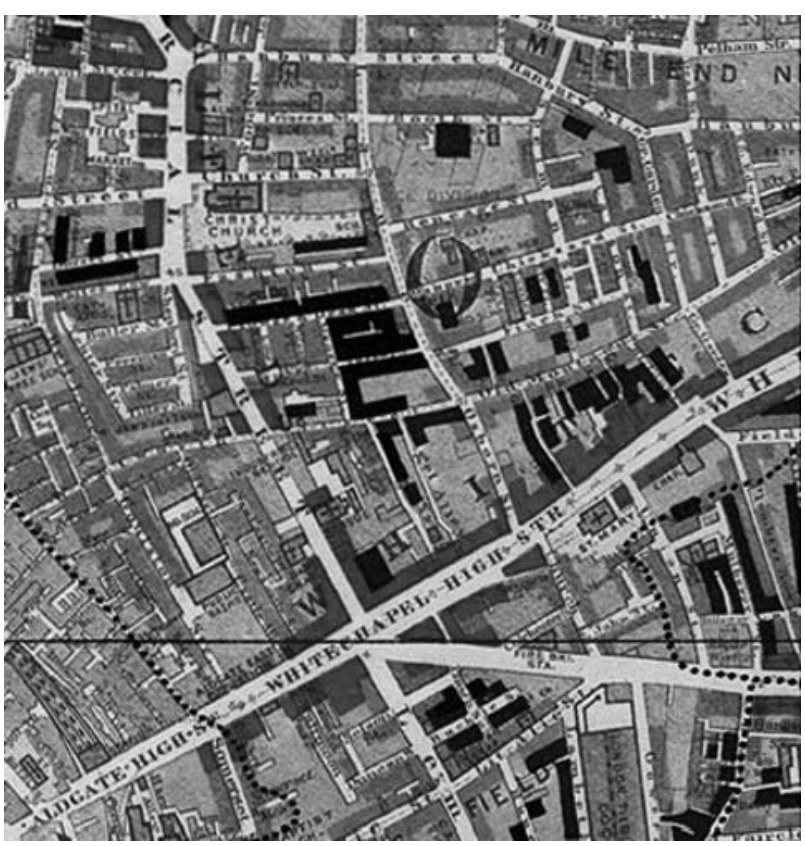

Fig. 14. Fragment of Ch. Booth poverty map of London [27].

Currently, it is very difficult to imagine spatial planning, crisis management or investment design without the use of spatial 3D data. In order to create such spatial models, various measurement techniques are applied, such as: data from terrestrial and aerial laser scanning, digital terrain model (DTM), digital land cover model (DLM), aerial photographs and images taken by unmanned aircraft, satellites and radars. In many countries 3D models of entire cities are created basing on such spatial data, an example of which may be a project by Polish Head Office of Geodesy and Cartography, which will include 3D models of buildings located throughout Poland, as well as devising tools which enable access to the information using an Internet browser. International standard CityGML 2.0, issued by Open Geospatial Consortium, was selected as the format to record $3 \mathrm{D}$ building models. All models will be designed with the LoD 2 [29]. Basing on the prior experience of numerous countries, it can be unequivocally stated that $3 \mathrm{D}$ e-services are and will continue to be widely applied in various types of analyses, such as, e.g.: visualizations applied in navigation, urban planning, visibility and shading analyses, measuring of terrain height and its solar potential, facility management, identification of aircraft obstacles, creation of thematic maps, as well as simulations and modelling of various phenomena, such as, rescuing missions or noise emission in urban settlements [4, 29-31]. What is also worth mentioning is the possibility of using $3 \mathrm{D}$ data in the inventory processes. Three-dimensional building models are used in spatial planning as well as architecture and urban planning. It is worth noticing that $3 \mathrm{D}$ data an e-services are also sources used by experts in promotion and marketing of towns and regions. The abovementioned examples of application of such data serve as proof of its immense potential. Depending on expected results, 3D 
models might be texture mapped using such techniques as photogrammetry and laser scanning [32].

There has been intensive ongoing work on technologies enabling creation of fully virtual environments, which would integrate the elements of physical with virtual activities (augmented reality). Soon, the screen used as the means of sharing information might be replaced by three-dimensional space. There are numerous tools, as well as open-source software, which might be used to display various cartographic representations, e.g. Google, as well as software tools and technologies enabling presentation of statistical data on digital maps in a browser, e.g. solutions provided by Google [33]. The applications are interactive and might be quickly updated, moreover, their content might be easily changed using available libraries and own models created with the use of such tools as SketchUp software, which later may be shared in Google Earth, a program which contains numerous detailed representations of popular structures and sights from all over the World.

\section{Summary}

When analyzing city maps the way of arranging facilities on them may be simplified with the use of the following taxonomy: symbolism in antiquity and Middle Ages, transition towards realism in the Renaissance and later gradual distinction between cartographic representations and painting imagery. At that time two-dimensional representations were dominant in cartography and the standardization of symbols for structures viewed from above was commenced. The end of 18 th century is the time when symbols were commonly used instead of images, which led to losses in decorativeness together with the increase in transparency and precision [17]. From the beginning of 17 th century, city maps and urban panoramas were often presented in the form of imponderables, which harmoniously combined art and science. During the period of Enlightenment maps began to have more scientific character and their authors resigned from "unnecessary decorative elements". 19th century marks the era of cartography, popularization of thematic maps and a pivot towards geoinformation precise location of structures. The representations were mainly two-dimensional, with satisfying accuracy and in accordance to the requirements of the representation scale.

$20^{\text {th }}$ century is a breakthrough in the history of maps. Transition from paper to the digital format, as well as systems of geographic information led to immense changes in cartography.

First interactive maps were not always created in accordance with cartographic good practices. The same issue occurs with automatically created $3 \mathrm{D}$ city models. Their representations are accurate in terms of geometry, nevertheless, they do not always meet the requirements of correct perception, due to a big number of details, selection of colors, textures, descriptions and map symbolization. 3D city models may have a wide application, that is why, in order to present them effectively, it is also necessary to bare in mind the quality of their visual representation. The authors suggest that one of the solutions which would improve the quality of visual presentation would be the inclusion of graphic designers in the designing process.

It is also necessary to bare in mind the issue of understanding and experiencing space through the use of new technologies. Virtual reality is not a copy of real urban area due to perception differences. In analyses of spatial models which map real structures other cognitive relations occur, which change our visual perception of, e.g. the body of the structure. As an example of such phenomenon might serve the study conducted by researchers from Bío-Bío University in Concepción, Chile, whose results led to the conclusion that in virtual space notions such as neighborhood and distance lose their importance and that intangibility of virtual space significantly weakens the perception of the organization of form [34-35]. In the view of the above, studies which strongly rely on such features as: visibility, assessment of localization and aesthetics, for instance urban analyses, when conducted basing on digital reality, may lead to faulty conclusions if the differences in perception are not acknowledged.

In classically managed cities two causes of insufficient use of geoinformation were noticeable: lack of appropriate resources of spatial data and, so called, silo (vertical, trade) urban resources management, including spatial data [4]. As a result of the development of new technologies, the technical ways of $3 \mathrm{D}$ and 4D presentation will have to be developed simultaneously with the advances in data processing and the increased accessibility of spatial data of various quality will be challenging for its users. A novelty in the attitude towards previously used representations is the necessity of evaluation of the quality of data and taking responsibility for newly created city models, which might be the basis for multiple and various decisions stemming from the Smart City philosophy. It does not mean that we have to abandon our imagination, moreover, it does not seem like this would happen anyway. Artists create their own visions, an example of which might be a popular collection of graphics entitled "GRAPHIC EUROPE an Alternative Guide to 31 European Cities" [36], which presents a return of emphasizing places important to the author with the means of drawing. There is also a plethora of visions presenting city development, such as this of Barcelona [37], or the design by Kevin Schopfer, who seems to have thought of everything in his NOAH (New Orleans Arcology Habitat) project, where he designed a railway and elevator network destined for the communication. Apart from standard functions, in the city there were also: several hotels, a casino and various other facilities [38]. Because, as Arthur C. Clarke said, "Any sufficiently advanced technology is indistinguishable from magic". 


\section{References}

1. Realm of History, https://www.realmofhistory.com, access 12.06.2016

2. E. Krzywicka-Blum, Map Functions (Springer International Publishing, Switzerland, 2017)

3. UN-GGIM, United Nations Initiative on Global Geospatial Information Management. Future trends in geospatial information management: the five to ten year vision, http://ggim.un.org, access 10.06.2017

4. D. Gotlib, R. Olszewski, Smart City. Informacja przestrzenna $w$ zarzadzaniu inteligentnym miastem (Państwowe Wydawnictwo Naukowe, Warszawa, 2016)

5. J.A. Wendt, Skarby kartografii (Wydawnictwo Arkady, Warszawa, 2013)

6. P.D.A. Harvey, [In:] D. Woodward, J.B. Harley (Eds.) The History of Cartography vol. 1 (University of Chicago Press, Chicago and London, 1987)

7. Wikimedia Commons, https://upload.wikimedia.org, access 02.06.2017

8. K. Bartel, Perspektywa malarska, tom II (Państwowe Wydawnictwo Naukowe, Warszawa, 1958)

9. W. Strzemiński, Teoria Widzenia (Wydawnictwo Literackie, Kraków, 1958)

10. Wikimedia Commons, https://upload.wikimedia.org, access 15.06.2017

11. Dassault Systèmes, https://www.3ds.com, access 15.06.2016

12. M. Pelletier, [In:] D. Woodward (Ed.) The History of Cartography vol. 3 (University of Chicago Press, Chicago and London, 2007)

13. G. Gatta, E. Arioti, G. Bitelli, Journal of Cultural Heritage 23, 68-76 (2017)

14. J. Brotton, Stynne mapy. Arcydzieła światowej kartografii $i$ ich tajemnice (Wydawnictwo Arkady, Warszawa, 2016)

15. Wikimedia Commons, https://upload.wikimedia.org, access 02.06.2017

16. Google Earth, https://www.google.com, access 02.06.2017

17. R. Rees, Geographical Review 70, 1, 60-78 (1980)

18. C. Moffatt, Leonardo da Vinci and mapmaking, http://faculty.virginia.edu, access 20.06.2017

19. F. Fiorani, [In:] D. Woodward (Ed.) The History of Cartography vol. 3 (University of Chicago Press, Chicago and London, 2007)

20. E. Szpakowska, Przestrzeń i Forma 16, 121-154 (2011)

21. Wikimedia Commons, https://upload.wikimedia.org, access 27.07.2017

22. M. Poznański, Stare Miasto - Zamość, http://lublin.wyborcza.pl, access 10.10.2017
23. Wikimedia Commons, https://upload.wikimedia.org, access 17.06.2017

24. Moscow Plans, http://abodye.ru, access 01.07.2017

25. M.H. Edney, M. Pedley (Eds.) Cartography in the European Enlightenment Volume 4 (The University of Chicago Press, 2018)

26. Wikimedia Commons, https://upload.wikimedia.org, access 16.03.2017

27. Wikimedia Commons, https://upload.wikimedia.org, access 15.03.2017

28. M. Monmonier, Cartography in the Twentieth Century (University of Chicago Press, 2015)

29. Zespół ds. 3D w projekcie CAPAP w GUGiK, Geodeta 9, 22-25 (2017)

30. M. Konecny, S. Zlatanova, T.L. Bandrova, Geographic Information and Cartography for Risk and Crisis Management (Springer-Verlag Berlin Heidelberg, 2010)

31. F. Biljecki, J. Stoter, H. Ledoux, S. Zlatanova, A. Çöltekin, ISPRS Int. J. Geo-Inf. 4, 2842-2889 (2015)

32. Ch. Frueh, R. Sammon, A. Zakhor, Proceedings of the 2nd International Symposium on 3D Data Processing, Visualization, and Transmission (2004)

33. K. Król, GLL 2, 91-106 (2016)

34. R. Zapłata, Quart 1-2, 124-137 (2017)

35. A. Asanowicz, Architecturae et Atribus 4, 5-12 (2012)

36. Z. Hanaor, GRAPHIC EUROPE an Alternative Guide to 31 European Cities (Cicada Books Limited, London, 2009)

37. Kaspersky, Earth 2050, http://adsoftheworld.com, access 27.07.2017

38. E.K. Schopfer, NOAH (New Orleans Arcology Habitat), http://homedesignmini.blogspot.com, access 27.07.2017 